\title{
Joachim Du Bellay, La Deffence, et illustration de la langue françoyse
}

\section{Dario Cecchetti}

\section{(2) OpenEdition}

1 Journals

\section{Edizione digitale}

URL: https://journals.openedition.org/studifrancesi/40461

DOI: 10.4000/studifrancesi.40461

ISSN: 2421-5856

Editore

Rosenberg \& Sellier

\section{Edizione cartacea}

Data di pubblicazione: 1 juillet 2004

Paginazione: 171-172

ISSN: 0039-2944

\section{Notizia bibliografica digitale}

Dario Cecchetti, «Joachim Du Bellay, La Deffence, et illustration de la langue françoyse», Studi Francesi

[Online], 142 (XLVIII | I) | 2004, online dal 30 novembre 2015, consultato il 09 septembre 2021. URL: http://journals.openedition.org/studifrancesi/40461; DOI: https://doi.org/10.4000/studifrancesi. 40461

Questo documento è stato generato automaticamente il 9 septembre 2021.

\section{(c) 9 (i) $\Theta$}

Studi Francesi è distribuita con Licenza Creative Commons Attribuzione - Non commerciale - Non opere derivate 4.0 Internazionale. 


\title{
Joachim Du Bellay, La Deffence, et illustration de la langue françoyse
}

\author{
Dario Cecchetti
}

\section{NOTIZIA}

JOACHIM DU BELLAY, La Deffence, et illustration de la langue françoyse, par FRANCIS GOYET et OLIVIER MILLET (Euvres complètes, sous la direction d'OLIVIER MILLET: $\mathrm{I}^{\text {er }}$ volume), Paris, Champion, 2003, pp. 461.

1 È il primo volume di una nuova edizione delle opere complete di Du Bellay (dopo quella di Henri Chamard, 1908-1931, completata da Geneviève Demerson, per le opere latine, 1984-1985). Quest'edizione si propone di pubblicare le pièces isolate e le raccolte di Du Bellay nell'ordine cronologico in cui esse videro la luce (e senza isolare la produzione latina da quella francese): così il primo volume, che edita la Deffence, la fa precedere dal più antico testo poetico pubblicato da Du Bellay, una breve composizione in onore di Jacques Peletier du Mans (Cesse, Le Mans, de prendre gloire), del 1547. La Deffence è un'opera costantemente al centro degli interessi della critica: recentissirna (Genève, Droz, 2001) è un'edizione a cura di Jean-Charles Monferran (cfr. questi «Studi», $n^{\circ} 138$, 2002, pp. 681-682), che tra l'altro ha il merito di offrire, in dossier, il Quintil horatian di Aneau e la Replique di Des Autels, come pure il testo integrale della traduzione francese fatta da Claude Gruget del Dialogo delle lingue di Speroni. L'edizione qui recensita si distingue, oltre che per il rigore testuale, per un Commentaire (pp. 91-433), costruito come ampia e densissima monografia sulla Deffence che, facendo il punto su un secolo di studi, dalla fondamentale indagine di Pierre Villey sulle Sources italiennes de la "Deffense» (1908) al lavoro di Kees Meerhoff su Rhétorique et poétique au XVI siècle en France (1986), intende mostrare la coerenza del pensiero di Du Bellay, pur nel quadro di una rete di fonti e antecedenti in Italia e Francia. Francis Goyet, autore del suddetto Commentaire, ha in passato edito e annotato (Traités de poétique et de rhétorique de la Renaissance, Paris, Le Livre de Poche classique, 1990) l'Art poétique di Sébillet e il Quintil horatian di Aneau due testi che o precedono o entrano in polemica con la Deffence - insieme ad altri traités 
che la Deffence non potranno ignorare, come l'Art poétique di Peletier o la Rhétorique française di Fouquelin e l'Abrégé di Ronsard: in questo suo lavoro di studioso della retorica cinquecentesca vanno cercate le premesse del commento alla Deffence che qui recensiamo. Goyet, che già aveava segnalato la coerenza del pensiero avverso alla Deffence, vuole ora mostrare la coerenza del pensiero di Du Bellay, cercando sia di chiarire il significato di un terme-étendard, quale possiamo considerare il termine illustration, sia di ricostruire una volta di più - al di là della meccanica e a volte dispersiva ricerca di fonti - l'estetica dell'imitatio disegnata nel trattato del 1549. Giustamente Goyet sottolinea come «uno dei problemi cruciali posti dalla Deffence sia quello dell'imitatio o innutrizione, della capacità che ha Du Bellay di fare suoi dei framrnenti presi a destra e a sinistra, preliminare necessario all'illustration. Il lavoro della critica a questo riguardo conduce, però, a una situazione quasi irnbarazzante. Più si scoprono nuove fonti, più si è pervasi da una sensazione di patchwork. L'analisi rischia di avere la meglio sulla sintesi, la molteplicità sulla coerenza» (p. 94). D’altra parte, sempre Goyet, riconosce come il sapore della Deffence sia proprio nella sua instabilità di fondo, dovuta ai diversi fili che Du Bellay intreccia (Speroni, Cicerone per la mediazione di Jacques-Louis d'Estrebay, ecc.), ma nello stesso tempo ribadisce che «possiamo immaginare un'unità che non sia stabilità, un'unità nel movimento che ricostituisca almeno la dinamica generale, nel momento in cui ci rendiamo conto del come le forze in gioco formino un'opera» (p. 95). Se é vero il rimprovero di Sébillet a Du Bellay di avere «mot à mot traduit des aultres», è anche vero che il risultato non è un centone, un patchwork, ma è nel tradurre e nell'imitare che si costituisce l'«inventare» secondo un'estetica assolutamente coerente. L'imitatio creatrice si situa in una prospettiva dinamica in cui i prestiti sono riappropriazione. Per evidenziare l'unità dinamica della Deffence Goyet ripercorre alcuni testi che egli definisce textes-matrices: si tratta dell'Avis au lecteur che precede l'Olive del 1549, della Manière de bien traduire di Dolet, dell'Orator di Cicerone e, infine, del Dialogo delle lingue, in una revisione fortement à la baisse delle considerazioni di Villey sull'apporto di Speroni. Con un lavoro di scavo interpretativo Goyet, pertanto, va ben al di là della ricerca puramente erudita, per quanto minuziosa, di fonti, e offre una riflessione globale sull'estetica di Du Bellay - e del Rinascimento che viene considerata nei suoi risvolti ideologici ma anche sociali. Il Commentaire è seguito da una sezione di Variantes et notes (pp. 371-411), di un repertorio analizzato e commentato degli emprunts dal Dialogo speroniano (pp. 412-426), da indici accurati, fra cui particolarmente utili quello degli italianismi segnalati da Aneau e quello delle nozioni commentate. Si tratta, per concludere, di un lavoro ponderoso, che offre un ottimo strumento di lavoro. 